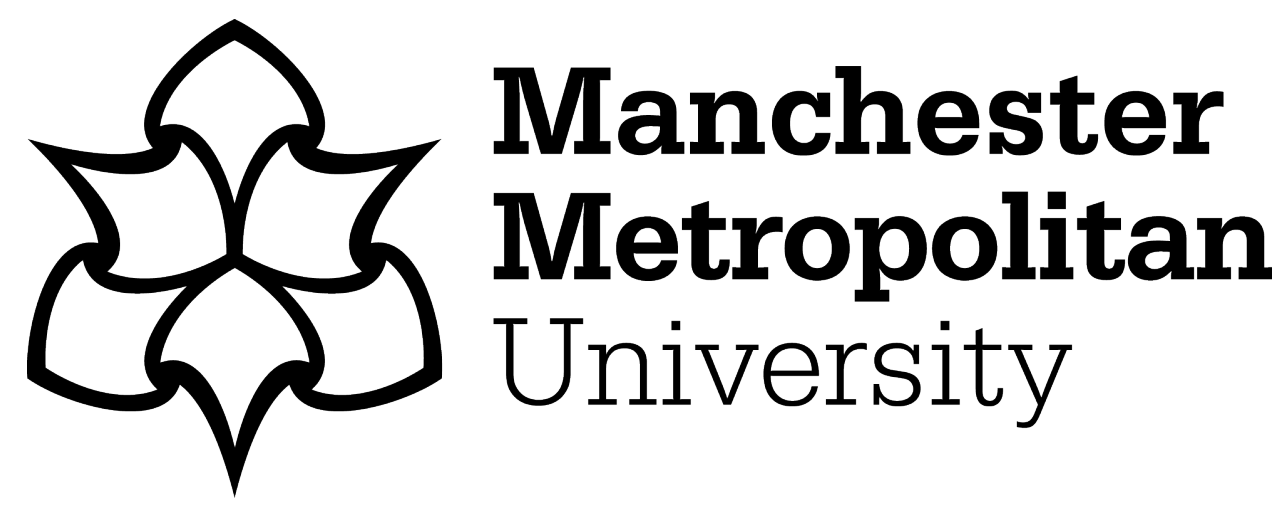

Parry, Sarah ORCID logoORCID: https://orcid.org/0000-0002-5666-1997, Carr, Natalie, Staniford, Leanne and Walker, Lucy (2022) Rebuilding the Workplace to Promote Young Workers' Mental Health. International Journal of Workplace Health Management, 15 (3). ISSN 1753-8351

Downloaded from: https://e-space.mmu.ac.uk/629034/

Version: Accepted Version

Publisher: Emerald

DOI: https://doi.org/10.1108/IJWHM-10-2021-0188

Please cite the published version 


\begin{abstract}
Purpose

Young adults have been particularly adversely affected by COVID-19 related disruptions, especially in relation to industries with an over-representation of young adults. This report discusses findings from survey data from young adults who reported poorer mental health comparative to older generations prior to the pandemic. Drawing on international literature and our research findings, we propose recommendations for rebuilding the workplace postpandemic to support young adult's mental health.

\section{Design and methodological approach}

Data from 1,999 respondents (aged 16-29, 30-44, 45-59 and 60+) from 200 organisations in the United Kingdom were sought in relation to workplace wellbeing and mental health through a 15 -item multiple choice online survey. Overall, $17 \%$ of the sample were senior management, $31 \%$ junior management, $37 \%$ in non-management roles and a further $15 \%$ stated 'other'. Exploratory quantitative analyses were undertaken to assess differences in responses to questions between age groups.
\end{abstract}

\title{
Findings
}

Participants in the 16-29-year-old age group were more likely than any other age group to report that work adversely affected their mental health. They reported their mental health challenges influenced their performance at work, that they had witnessed colleagues' employment negatively influenced by mental health challenges, and they felt more comfortable citing physical health challenges for absence over mental health difficulties.

\section{Originality}

COVID-19 related disruptions meant a large-scale move to remote working for many people. As we return to physical workplaces, we have an exciting opportunity to reform and improve the status quo. Our findings in relation to the mental health of young adults highlight key risk factors that need to be addressed.

Key words: Young adults, mental health, improving workplaces, wellbeing, quantitative 


\section{Rebuilding the Workplace to Promote Young Workers' Mental Health}

Work-related stress is a serious occupational health problem that has been subject to a substantial body of research in recent years (Harvey et al., 2016). Due to the amount of time people spend at work, the working environment can have a strong impact on physical and mental health (Aristotelis et al., 2015). Beyond the negative impacts of workplace stress on the health of employees, stress at work can adversely affect companies in terms of productivity and absenteeism (Ippoliti et al., 2017). Employers and workplaces have both the opportunity and responsibility to promote the wellbeing of their workforce, for both psychosocial and economic reasons (Tarroet et al., 2020). Due to the interrelated nature of mental health difficulties in the working age population and workplace, indirect costs to employers of not supporting employees can be significant (Gaillard, Sultan-Taïeb, Sylvain and Durand, 2020).

According to the most recent analytics in the United Kingdom (UK; Deloitte, 2020), the cost of mental health difficulties to employers is rising. The cost of mental health difficulties to employers in 2019 causing absenteeism, rapid turnover and decreased productivity was $£ 45$ billion. Investment in health promotion interventions can be highly beneficial as employers are likely to see a $f 5$ return for every $£ 1$ spent on mental health interventions, making mental health promotion initiatives a benefit to all (Deloitte, 2020). However, stigma is often a barrier to taking part in such interventions. Therefore, the primary intervention should be to reduce stigma within organisations to remove barriers to help-seeking for employees, before rolling out health promotion interventions for individuals who may not feel able to opt-in (Nogues and Finucan, 2018). Importantly, employees with experience of mental health difficulties can hold unique skills and qualities that can be particularly helpful at work (Hennekam, Follmer \& Beatty, 2021). For example, the experience of overcoming mental health difficulties and engaging in therapy can increase self-awareness, empathy, effective coping strategies, and enhance personal resilience (Roe, et al., 2010; Wan Mohd Yunus, Musiat, and Brown, 2018). Therefore, employers should focus upon supportive and inclusive employment practices to enhance the retention of a skilled and resilient workforce.

Age is also a key demographic variable that can play a vital role in experiences of workrelated stress. A meta-analyses of over 800 articles demonstrated older workers generally report higher levels of job satisfaction and lower work-related stress, and recommended 
research examines the role of age group more closely across international organisations $(\mathrm{Ng}$ and Feldman, 2010). For example, older managers in a Hong Kong based study appeared to experience lower levels of stress than their younger counterparts (Siu et al., 2010). In contrast, research with nurses in the UK has identified nurses later in their careers reported higher levels of work-related stress and poorer psychological health than younger nurses (Kirkaldy and Martin, 2000). However, a recent Ghanaian study with nurses and midwives found younger age and perceived organizational support important influences upon emotional exhaustion (Lartey et al., 2021). Lartey argues that older professionals can draw on greater professional and personal experiences to help buffer against emotional exhaustion from work. Other studies have reported an inverted U-shaped relationship with age and stress, with middle-aged workers experiencing the highest levels of stress (e.g. Rauschenbach and Hertel, 2011). Possible reasons for these varied trends include professional trajectories, that workers in their mid-life may typically have more responsibilities in their work and personal life roles (i.e. raising a family, caring for aging relatives, etc.), and multiple simultaneous occupations and caring responsibilities typically impact women more than men (Kelle, 2018). During the pandemic, it has also been suggested that the additional cognitive demands, requirements and invasiveness of working through technology in the home added to tensions for caregivers working from home (Ghislieri et al., 2021).

A recent international scoping review identified that the finance, education, healthcare and technology sectors were most generous in terms of supporting a caregiver-friendly workplace; with support services, paid leave, and flexible work arrangements helpful mechanisms for caregivers (Lorenz et al., 2021). It may be particularly productive to focus research around vocational and artistic professions that are associated with a passion or devotion to one's work as people described as 'work-devoted' demonstrated relatively positive psychological and physical health in a recent work investment study (Snir and Harpaz, 2021). Overall, whilst caution should be embraced around generalisations, age clearly plays a role in work-related distress, although further research is warranted to explore the nuanced mechanisms that may affect age groups across professions and workplaces as there are clearly important differences across sectors and professions. 


\section{Mental Health Risk Factors for Young Adults}

Risk factors associated with the COVID-19 pandemic such as social isolation, unemployment, housing and income uncertainties, and work-related stress have particularly affected young adults (Carbone, 2020). Anxiety, depression, poor sleep, substance reliance and suicidal thoughts have risen for 18-24-year-olds during the pandemic (Panchal et al., 2021). Further, the move to remote working so early on in one's career has been cited as an additional stressor for young people (Panchal et al., 2021). Whilst it is too soon to know all of the mechanisms that cause remote-working distress, it is reasonable to hypothesize that one reason remote working may bring additional stressors is a loss of implicit, experiential learning opportunities through observation and scaffolded learning that often supports early career workers in physical workplaces (Miller, 2019; Taylor and Hamdy, 2013), practically and emotionally.

Additionally, demands including quantitative workload (Pulkki-Ranack et al., 2016), emotional strains (Bonde, 2008), interpersonal conflicts at work, organisational constraints (Baka, 2015), and organisational injustices (Theorell et al., 2015) have all been identified as predictors of depressive symptoms. Workplace bullying in particular has been connected to increased workplace stress, lower levels of occupational health and reduced wellbeing (Yoo and Lee, 2018). Young women with lower self-esteem may be most likely to experience workplace bullying (López-Cabarcos, Vázquez-Rodríguez \& Gieure, 2017). Another risk factor correlated with workplace stress is long working hours, which affect the work-life balance. However, control of one's diary and greater flexibility in relation to working tasks reduces work-related stress (Hsu et al., 2019). Other commonly cited risk factors include role ambiguity, lack of autonomy and a lack of support from supervisors (Arcangeli, Girogi, Montali \& Sderci, 2019). In some professions, such as in academia (Susi et al., 2019) and medicine (Morrow et al., 2014), long, unpredictable and unsociable hours are often expected from those early on in their careers and seen as part of the early career culture. In other industries, such as hospitality where young people often form the majority of the workforce, long unsociable hours and a variety of other factors (Ariza-Montes et al., 2019) have also been found to lead to reduced quality of life (Roan and Diamond, 2018). Consequently, it seems young adults are exposed to more risk factors and fewer protective factors due to their age and career stage. 
Existing mental health challenges also influence people's experiences of their work. Importantly, around one in five people aged 16-24-years and one in three young women aged 16-24-years in the UK report mental health difficulties, such as anxiety and depression (ONS, 2020). The pandemic has seen mental health challenges increase specifically for women, young adults (18-29 years), people from socially disadvantaged backgrounds, and those with pre-existing mental health difficulties (Connor et al., 2020). Clearly there are multiple factors that contribute to experiences of work-related stress and impact employees mental health and wellbeing, including sociodemographic variables (e.g. age, gender, job level) and jobspecific variables (e.g. job demands, job control, job satisfaction, support from colleagues and supervisors).

\section{Coping with Challenges}

The added and amplified risk factors that have emerged through the pandemic mean it is even more essential we recognise effective coping strategies and find opportunities to promote health coping within and outside of work. Coping is defined as the cognitive and problem-solving behaviours we employ to tolerate, alleviate and reduce distress (Lazarus \& Folkman, 1984). Developing the agency and resources to choose effective coping strategies can reduce the impact of work-related stress and the occurrence of stress-related diseases (Bhagyalakshmi et al., 2012).

Workplace wellbeing interventions have adopted varying strategies with fluctuating degrees of success. For example, interventions that have targeted employee resilience have shown promise in reducing symptoms of stress and anxiety (Kunzler et al., 2020). Resources and interventions that have been linked to having the potential to reduce workplace stress include mindfulness based cognitive therapy (Hente et al., 2020), yoga, peer supervision and formal debriefing in some scenarios (Jarden et al., 2019), with some evidence from healthcare settings suggesting that participation in workplace wellness activities can reduce workplace stress (Ledikwe et al., 2018). However, the heterogeneity in interventions and evaluations means it is difficult to draw meaningful conclusions on efficacy.

Research conducted during the pandemic has demonstrated that the home-based workplace has intensified work for many, with online presenteeism cited as a stress factor, and employment insecurity and poor adaptation to new ways of working potentially affecting 
younger adults with greater severity (Adisa et al., 2021). As offices and physical workplaces begin to welcome back their employees following waves of COVID-19 and related disruptions, we have an exciting and important opportunity to consider how we can create something better than we had before. Young adults have been particularly adversely affected by the pandemic socially, emotionally and economically. Therefore, workplaces and professional bodies have an imperative role to play in improving working conditions for these young adults, which will benefit all in the long-term.

The current study aimed to identify self-reported factors that influence people's wellbeing in the workplace across a range of settings and age groups, with a particular focus upon young working age adults. Greater understanding of these mechanisms could inform professional practice and policy recommendations, multisystemic support structures, and guide workplaces in recreating the workplace post-pandemic for the benefit of all, particularly those at an early career stage who have generally been most adversely affected.

\section{Method}

Design

Data was collected in the UK in October 2019 through a 15-item multiple choice online survey by GingerComms. GingerComms is a survey-led big data company that operates across multiple media platforms in the UK and globally. The target sample size for the data collection was 2,000. In total, 2,011 UK respondents took part. As the data was acquired through market research and not originally designed for academic research purposes, an exploratory statistical research design was adopted, focusing on the impact of age group upon workplace stress.

\section{Participants}

2,011 individuals from 200 UK based organisations responded to the online questionnaire, self-selecting take part Participants were recruited from all areas of the UK and demographic data was provided in relation to age, gender, working role, geographical location and industry. Just over half of the sample comprised of females ( $N=1051)$. The majority of participants were aged 30-44 ( $N=832)$, with about a quarter aged 16-29 $(\mathrm{N}=544)$ and another quarter comprising of those aged 45-59 $(\mathrm{N}=524)$. The smallest age group were 
those aged 60 and over $(N=111)$. In terms of workplace position, $17 \%$ of the sample were senior management, $31 \%$ junior management, $37 \%$ were in non-managerial roles, and a further $15 \%$ stated 'other'. London was reported as being the nearest city for most participants (13.03\%). The next highest number of participants reported their nearest cities as Brighton (9.20\%), Manchester (8.55\%) and Birmingham (8.25\%). The cities with the lowest number of participants were Stoke on Trent (0.90\%), Belfast (1.74\%), Norwich (2.19), Leicester $(2.69 \%)$, Liverpool $(2.83 \%)$, and Sheffield $(2.88 \%)$. The majority of participants reported working in retail/wholesale trade $(12.53 \%)$, healthcare $(10.59 \%)$ and education (8.8\%).

\section{Measures}

The survey included items regarding demographic information including, gender, age, occupation, work position and location of work. The 15 multiple choice items were designed by GingerComms, each relating to an aspect of workplace support and mental health (Table I). For the purposes of data analysis, eight of the 15 questions were assessed for differences between age groups, while the remaining seven questions were not suitable for inferential analysis.

\section{$<$ INSERT TABLE 1>}

\section{Analytic Approach}

The data set was anonymised and then securely transferred to the research team for analysis. Following the cleaning and cataloguing of the data set, statistical analyses were undertaken. Participants provided informed consent to take part through GingerComms and ethical approval for the transfer and analysis of data was gained through the Research Ethics Committee of the host University.

Initially, exploratory analyses of the survey questions were undertaken to understand the effects of age on participant responses. $N=12$ were removed from the analysis as these participants responded to 'occupation' as 'wife/husband' so there was ambiguity as to the 'workplace' they reported on. Perhaps of interest, this group appeared to be the most dissatisfied with their 'workplace' and 'employer' overall. However, for the purpose of clarity, their data was removed prior to the final analysis. Consequently, data from 1,999 participants 
formed the final analysis. Participants who answered 'prefer not to say' or left the response blank were also removed from the analysis for each individual question. Data was analysed using SPSS v26, non-parametric tests (Kruskal-Wallis) were used due to the non-parametric and ordinal nature of the data, to assess differences in responses to questions between age groups. Results were adjusted for multiple comparisons (Bonferroni) and alpha levels are reported as .05 .

Exploratory analyses were run based on participant data from the most socioeconomically deprived and wealthiest locations, but no significant differences were found in responses. Differences between professional groups and gender were also nonsignificant (analyses provided as supplementary material). The most significant indicator for how people experienced their mental health in the workplace was age group.

\section{Results}

Table II reports results from the eight questions (see Table I), exploring differences in age group responses.

<nsert Table 2>

Significant differences in response to Q2 (having a mental health issue that impacted participants performance at work) was observed between the four different age groups (Table II). Dunns Post hoc pairwise comparisons indicated that 16-29-year olds reported significantly higher impact of mental health on job performance than $30-44$-year olds ( $z=129.24$, SE 30.27, $p<.001), 45-59$-year olds $(Z=240.07, \mathrm{SE33.57}, p<.001)$, and those aged $60+$ (difference $z$ $=391.04$, SE57.17, $p$ <.001). Additionally, 30-44-year olds reported higher impact than those aged $60+$. ( $z=261.80$, SE55.50, $p<.001)$ and those aged $45-49-$ year olds ( $z=110.84$ SE 30.64, $p=.002)$

Significant differences were also observed in response to Q4 (called in sick because you felt mentally low/unwell but told your work you were physically unwell) between the four different age groups (Table II). Dunn post hoc pairwise comparisons indicated that $60+$-year olds reported significantly less instances of reporting physical ill health in place of mental health issues than 45-59-year olds ( $z=166.31$, SE 57.84, $p=.024)$, 30-44-year olds $(z=319.95$, SE 55.97, $p<.001)$, and those aged 16-29 ( $z=372.63$ SE 57.64, $p<.001)$. Additionally, 45-59- 
year olds reported less instances than those aged 30-44 ( $z=153.64$, SE 30.85, $p<.001)$ and 16-29-year olds ( $z=206.32$ SE 33.78, $p<.001$ )

Results for Q5 (feeling mentally unwell as a result of or made worse by work) also revealed significant differences between the age groups surveyed. Dunn post hoc pairwise comparisons 60+-year olds reported statistically significantly lower reports of feeling mentally unwell than 45-59-year olds ( $z=175.34$, SE56.52, $p=.012$ ), 30-44-year olds $(z=230.50, \mathrm{SE}$ $54.69, p<.001)$, and those aged 16-29 ( $z=281.10$ SE 56.32, $p<.001)$. Additionally, 45-59-year olds reported less instances than those aged 16-29-year olds ( $z=105.76$ SE 33.01, $p=.008$ ).

Lastly, differences could also be observed between age groups for Q7 (experiences of a colleague made redundant or demoted due to mental health reasons). Dunn post hoc pairwise comparisons indicated that those aged 16-29-years old had higher levels of experiencing colleagues being pushed out due to mental health than those aged 45-59-year olds $(z=204.01$, SE 31.75, $p<.001)$ and those aged $60+(z=271.65$, SE 54.17, $p<.001)$. Furthermore, those aged 30-44-year olds also had higher levels of experiences than those aged 45-59-yeard old $(z=150.83$, SE 28.99, $p<.001)$ and those aged 60+ $(z=218.47$, SE 52.60, $p<.001)$.

\section{Discussion}

In summary, younger participants reported their mental health could be adversely affected by their work and younger participants were more likely to report a physical health complaint when they were absent from work over a mental health issue, even if the true cause was a mental health related challenge. This large-scale survey sought to identify the role of age group at work and has highlighted that the mental health of young adults is both affected by their work and affects them in their work, significantly more so than their older colleagues. Participants in the 16-29-year-old age group (emerging/young adults, DoveyPearce et al., 2005) were more likely than any other age group to report that they had known colleagues who had been made redundant or demoted as a result of poor mental health. Finally, older age was found to be a protective factor against the impact of existing mental health challenges on work performance, perhaps due to an interplay of work-related experience and learnt copings strategies over time. It would be helpful for qualitative and mixed methods research to explore mechanisms that support older people in relation to their 
mental health at work to see what mechanisms could be translated to younger age groups to support their wellbeing. Mentorship and buddying programmes could also be helpful to this end.

Research conducted during the pandemic has highlighted that those with a lower household income are more likely to experience higher levels of stress (Panchal, et al., 2021), which is another risk factor for young people at an earlier career stage who are often on lower incomes than their older colleagues. Additionally, the comprehensive review of Kniffin, et al. (2021) cite Murthy's work (2017) that recognised loneliness was an epidemic for young people long before the pandemic emerged, which has been compounded by being furloughed and working from home during COVID-19 disruptions. Workplace loneliness has been associated with poorer workplace relationships and performance (Ozce-lik and Barsade, 2018). Research prior to the pandemic suggests people aged younger than 25 -years and those aged over 65-years demonstrate the highest levels of loneliness, with young adults experiencing loneliness at particular risk of poor physical health and loneliness (Victor \& Yang, 2012). Post-pandemic working environments will need to provide opportunities for good quality social interactions, which are beneficial for health (Mogilner et al., 2018). Consequently, ensuring workplaces, spaces and meetings offer meaningful opportunities for positive social interaction for young people is particularly important as workplaces respond to the impact of COVID-19.

The social, economic and environmental repercussions of COVID-19 will change how we work in future, perhaps leading to blended virtual and physical working practices longterm (Kniffin, et al., 2021). From a strengths-based perspective, young people could be well placed to support this shift in terms of technical competencies. However, we also need to be mindful to nurture known protective factors for wellbeing at work such as control of one's diary, flexibility over working hours (Hsu et al., 2019) and avoid known stressors such as role ambiguity, lack of autonomy and a lack of support from supervisors (Arcangeli, Girogi, Montali \& Sderci, 2019).

It has been proposed that workplaces are well placed to contribute to the prevention of mental health difficulties during and after COVID-19 through evidence-based workplace wellbeing programmes (Carbone, 2020). Although stigma can be a barrier to accessing some interventions at work (Nogues and Finucan, 2018), the existence of COVID-19 could be a 
facilitator to engagement as to varying degrees, everyone has lived experience of the pandemic, which could act as a leveller to reduce stigma surrounding related distress. Further, it is recognised that frontline health and social care workers who have experienced both the personal and professional stressors of the pandemic, and quite possibly secondary traumatic stress from supporting vulnerable others, should be prioritised for mental health support at work (Torales et al., 2020). However, we can transfer much of what is known to be helpful and beneficial for health and social care workers to other settings as well. For example, to feel valued, a sense of belongingness, and to feel emotionally supported at work (Parry, 2017) are human needs, not necessarily specific to certain caring professions. Further, multisystemic approaches and organisation wide responsibility for staff support are likely to be more effective than tasking individual managers or managerial levels with staff wellbeing (Parry et al., 2021).

Although this study offers novel data from a relatively large sample, there are a number of limitations and areas for further study. The questions posed to participants were developed by a market research company and the research team would recommend future surveys do not pose questions with more than one part. For example, 'Have you ever felt mentally unwell (e.g. stressed, anxious, depressed) either as a result of, or made worse by, your job?' could have been posed as two questions for further clarity and nuance of experience: (1)' Have you ever felt mentally unwell (e.g. stressed, anxious, depressed) as a direct result of your job?' (2) 'Has your mental health (e.g. feeling very stressed, anxious, depressed) been made worse by your job?'. Additionally, the survey did not request information about existing mental health difficulties or diagnoses so we cannot be sure how representative our findings are for the general popultaion, which limits transferability. However, it is encouraging that our findings align contextually with research around workplace wellbeing and mental health at work. It would be helpful if future research could explore some of the trends we have identified qualitatively to develop a more in-depth and nuanced understanding of mechanisms underpinning work-related health and some of the intersectional factors that may influence particular professions, such as female police officers reporting a lack of social support in a male dominated profession (Baka, 2020). As such, future research should seek to establish the sector in which participants work to allow for further 
sub-group analyses. Finally, opting for validated and reliable measures of wellbeing constructs would also be beneficial to draw comparisons across datasets over time.

To conclude, we recommend that a culture of social and professional learning support, validation and reassurance could help young people in the workplace recognise and report their mental health struggles so they can receive support and open communication channels with their support structures. Further research is needed to inform mechanisms to operationalise support for younger workers in particular, which are likely to vary enormously across professions and industries. Overall, our findings and the wider literature combine to suggest workplaces were not supporting the wellbeing or optimum productivity of young people before the pandemic. Young people have disproportionately experienced further adversity during COVID-19. Therefore, change is needed to support them in the near and current future throughout a period of readjustment and reform. Communication from organisational leadership also needs to recognise the responsibilities of organisations to create a supportive working environment, rather than expecting employees to be relentlessly resilient in the face of increasing pressures and uncertainty. Finally, providing opportunities for experiential learning with experienced colleagues, good quality social interaction amongst peers, promoting a culture of positive self-esteem and flexible working for people with caring responsibilities in particular could transform workplaces into wellbeing spaces, nurturing creativity, productivity, resilience and the retainment of talent, skills and implicit knowledge.

\section{Key Learning:}

- Further research is warranted to explore the nuanced mechanisms that may affect age groups across professions and workplaces to learn how coping mechanisms and systemic support may need to change to reflect age-specific needs.

- Mental health challenges have increased specifically for women, young adults, people from socially disadvantaged backgrounds, and those with pre-existing mental health difficulties during the pandemic. Originations should consider targeted and proactive support for these groups in particular during the recovery period from the pandemic.

- Loneliness is common amongst young adults and detrimental to physical and psychological health. Therefore, workplaces should carefully consider how to offer opportunities for good quality social interactions and experiential learning through 
senior colleagues upon the return to the workplace, particularly for young people who may have changed jobs and lack transferable skills and confidence.

- We can benefit from a knowledge mobilisation approach in three key areas:

1. nurture known protective factors for wellbeing at work such as control of one's diary, flexibility over working hours, clear boundaries and expectations;

2. avoid known stressors such as role ambiguity, lack of autonomy and a lack of support from supervisors;

3. we can transfer much of what is known to be beneficial for health and social care workers to other settings. For example, to feel valued, a sense of belongingness, and to feel emotionally supported at work. Ultimately, multisystemic approaches and organisation wide responsibility for staff support are likely to be more effective than tasking individual managers or managerial levels with staff wellbeing. 


\section{References}

Adisa, T.A., Ogbonnaya, C. and Adekoya, O.D. (2021). 'Remote working and employee engagement: a qualitative study of British workers during the pandemic.' Information Technology \& People, Vol. ahead-of-print No. ahead-of-print. https://doi.org/10.1108/ITP-12-2020-0850

Arcangeli G., Giorgi G., Montalti M., Sderci F. (2019) The Assessment of Work-Related Stress in a Large Sample of Bank Employees. In: Bagnara S., Tartaglia R., Albolino S., Alexander T., Fujita Y. (eds) Proceedings of the 20th Congress of the International Ergonomics Association (IEA 2018). IEA 2018. Advances in Intelligent Systems and Computing, 819. https://doi.org/10.1007/978-3-319-96089-0_51

Aristotelis., K., Giannouli, V., Drantaki, V., Angelian, S., Stratou, E., Saridi, M. (2015). The Impact of Healthcare Workers Job Environment on Their Mental-emotional Health. Coping Strategies: The Case of a Local General Hospital. Health Psychology Research, Vol. 3, No. 15, 10.4081/hpr.2015.1984.

Ariza-Montes, A., Hernández-Perlines, F., Han, H. and Law, R. (2019). Human dimension of the hospitality industry: Working conditions and psychological well-being among European servers. Journal of Hospitality and Tourism Management, Vol. 41, pp. 138-147. doi: 10.1016/j.jhtm.2019.10.013.

Baka, L. (2020). Types of job demands make a difference. Testing the job demand-controlsupport model among Polish police officers, The International Journal of Human Resource Management, Vol. 31, No. 18, 2265-2288. DOI: 10.1080/09585192.2018.1443962

Bhagyalakshmi, M., Ramana, B.M., Suresh, H and Raj, J. M. (2012). Assessment of the level of stress and coping strategies among patients with coronary artery disease. Journal of the Scientific Society, Vol. 39, No. 3, 136-140 (5). DOI: https://doi.org/10.4103/09745009.105918.

Bonde, J.P. (2008). Psychosocial factors at work and risk of depression: A systematic review of the epidemiological evidence. Occupational and Environmental Medicine, Vol. 65, pp. 438-445. 
Carbone, S.R. (2020). Flattening the curve of mental ill-health: the importance of primary prevention in managing the mental health impacts of COVID-19. Mental Health and Prevention, 19, https://doi.org/10.1016/i.mhp.2020.200185.

O'Connor, R.C., Wetherall, K., Cleare, S., McClelland, H., Melson, A. J., Niedzwiedz, C.L., Robb, K.A. (2020). Mental health and well-being during the covid-19 pandemic: longitudinal analyses of adults in the UK covid-19 mental health and wellbeing study. The British Journal of Psychiatry: The Journal of Mental Science, Vol. 1, No. 8, doi: 10.1192/bjp.2020.212

Deloitte (2020). Mental health and employers: refreshing the case for investment. Retrieved from https://www2.deloitte.com/uk/en/pages/consulting/articles/mental-health-andemployers-refreshing-the-case-for-investment.html

Dovey-Pearce, G., Hurrell, R., May, C., Walker, C. and Doherty, Y. (2005) 'Young adults' (1625 years) suggestions for providing developmentally appropriate diabetes services: a qualitative study.' Health \& Social Care in the Community, Vol. 13, pp. 409-419. https://doi.org/10.1111/j.1365-2524.2005.00577.x

Ghislieri, C., Molino, M., Dolce, V., Sanseverino, D., \& Presutti, M. (2021). 'Work-family conflict during the Covid-19 pandemic: teleworking of administrative and technical staff in healthcare. An Italian study.' La Medicina del lavoro, Vol. 112, No. 3, pp. 229-240. https://doi.org/10.23749/mdl.v112i3.11227

Gu, B., Tan, Q. and Zhao, S. (2019) 'The association between occupational stress and psychosomatic wellbeing among Chinese nurses: a cross-sectional survey.' Medicine, Vol. 98, No. 22

Gaillard, A., Sultan-Taïeb, H., Sylvain, C., and Durand, M. (2020) 'Economic evaluations of mental health interventions: A systematic review of interventions with work-focused components.' Safety Science, 132, https://doi.org/10.1016/j.ssci.2020.104982

Harvey, S.B., Milligan-Saville, J.S., Paterson, H.M., Harkness, E.L., Marsh, A.M., Dobson, M., Kemp, R. and Bryant, R.A. (2016) 'The mental health of fire-fighters: An examination of the impact of repeated trauma exposure.' Australian \& New Zealand Journal of Psychiatry, Vol. 50, No. 7, pp. 649-658. 
Health and Safety Executive. (2004) The role of work stress and psychological factors in the development of musculoskeletal disorders. [Online] [Accessed on 18th September 2020]

Hennekam, S. Follmer, K. \& Beatty, J.E. (2021) 'The paradox of mental illness and employment: a person-job fit lens.' The International Journal of Human Resource Management, 32(15), 3244-3271, doi: 10.1080/09585192.2020.1867618

Hente, E., Sears, R., Cotton, S., Pallerla, H., Siracusa, C., Filigno, S. S. and Boat, T. (2020) 'A Pilot Study of Mindfulness-Based Cognitive Therapy to Improve Well-Being for Health Professionals Providing Chronic Disease Care.' The Journal of Pediatrics, Vol. 224, pp. 8793.

Hsu, Y.Y., Bai , C-H., Yang, C-M., Huang, C., Lin, T.T., and Lin, C.H. (2019). Long Hours' Effects on Work-Life Balance and Satisfaction. BioMed Research International, Vol. 1, pp. 1-8. doi: 10.1155/2019/5046934.

Ippoliti F., Corbosiero P., Canitano N., Massoni F., Ricciardi M.R., Ricci L., Archer T., Ricci S. (2017). Work-related stress, over-nutrition and cognitive disability. Clinical Therapy, Vol. $168, \mathrm{e} 42-\mathrm{e} 47$.

Jarden, R.J., Sandham, M., Siegert, R. J. and Koziol-McLain, J. (2019) 'Strengthening workplace well-being: perceptions of intensive care nurses.' Nursing in Critical Care, Vol. 24, No. 1, pp. 15-23.

Kelle, N. (2020). Combining employment and care-giving: how differing care intensities influence employment patterns among middle-aged women in Germany. Ageing and Society, Vol. 40, No. 5, pp. 925-943. doi: 10.1017/S0144686X18001423

Kirkcaldy, B.D. and Martin, T. (2000). Job stress and satisfaction among nurses: individual differences. Stress and Health, Vol. 16, No. 2, pp.77-89.

Kniffin, K. M., Narayanan, J., Anseel, F., Antonakis, J., Ashford, S. P., Bakker, A. B., ... van, V. M. (2021). Covid-19 and the workplace: implications, issues, and insights for future research and action. American Psychologist, https://doi.org/10.1037/amp0000716 Kunzler, A.M., Helmreich, I., Chmitorz, A., König, J., Binder, H., Wessa, M., and Lieb, K. (2020). Psychological interventions to foster resilience in healthcare professionals. Cochrane Database Systematic Reviews, Vol. 5, No. 7. doi: 10.1002/14651858.CD012527.pub2. 
Lartey, J.K.S., Amponsah-Tawiah, K. and Osafo, J. (2021). 'Emotional intelligence and perceived organizational support as predictors of emotional exhaustion among nurses and midwives'. International Journal of Workplace Health Management, Vol. 14 No. 3, pp. 261-273. https://doi.org/10.1108/IJWHM-10-2020-0173

Lazarus, R.S., and Folkman, S. (1984). Stress, appraisal and coping. New York: Springer.

Ledikwe, J. H., Kleinman, N.J, Mpho, M., et al. (2018). Associations between healthcare worker participation in workplace wellness activities and job satisfaction, occupational stress and burnout: a cross-sectional study in Botswana. BMJ Open, Vol, 8. doi:10.1136/bmjopen-2017-018492.

López-Cabarcos, M. Á., Vázquez-Rodríguez, P., and Gieure, C. (2017). Gender and age differences in the psychosocial risk factors of workplace bullying. Psychology and Marketing, Vol. 34, No. 11, pp. 1023-1030.

Lorenz, F., Whittaker, L., Tazzeo, J. and Williams, A. (2021). 'Availability of caregiver-friendly workplace policies: an international scoping review follow-up study'. International Journal of Workplace Health Management, Vol. 14 No. 4, pp. 459-476. https://doi.org/10.1108/IJWHM-10-2019-0136

Malik, N., Naima, K., Björkqvist, K and Österman, K. (2017). Factors Associated with Occupational Stress among University Teachers in Pakistan and Finland. Journal of Educational, Health and Community Psychology, Vol. 6. 10.12928/jehcp.v6i2.7047.

Miller, F.Q. (2019), "Encountering relatable information in experiential learning spaces: A partnership framework for research information specialists and early career researchers", Journal of Documentation, Vol. 75 No. 3, pp. 517-529. https://doi.org/10.1108/JD-05$\underline{2018-0069}$

Morrow, G., Burford, B., Carter, M., et al. (2014). Have restricted working hours reduced junior doctors' experience of fatigue? A focus group and telephone interview study. BMJ Open, Vol. 4: e004222. doi: 10.1136/bmjopen-2013-004222

Ng, T.W.H., and Feldman, D. C. (2010). The relationship pf age with job attitude: A Meta Analysis. Personnel Psychology, Vol. 63, pp. 677-718 
Nogues, S., and Finucan, J. (2018) 'Economic Evaluations of Workplace Mental Health Interventions: A Critical Review.' Canadian Journal of Administrative Sciences, 35, 551562. https://doi.org/10.1002/cjas.1502.

Office for National Statistics. (2020). Young people's well-being in the UK: 2020. Retrieved from:

https://www.ons.gov.uk/peoplepopulationandcommunity/wellbeing/bulletins/youngpeo pleswellbeingintheuk/2020

Parry, S. (2017). Effective Self-Care and Resilience in Clinical Practice Dealing with Stress, Compassion Fatigue, and Burnout. Jessica Kingsley Publishers. ISBN 9781785920707

Pulkki-Ranack, L., Elovainio, M., Virtanen, M. , Kivimaki, M. , Hintsanen, M. , Hintsa, T. and Raitakari O.T . (2016). Job demands and job control as predictors of depressive symptoms: Moderating effects of negative childhood socioemotional experiences. Stress and Health, Vol. 32, pp. 383-394.

Parry, S., Williams, T., and Burbidge, C. (2021). Restorative Parenting: Delivering Traumainformed Residential Care for Looked-after Children. Child and Youth Care Forum, Journal of Research and Practice in Children's Services. doi: 10.1007/s10566-021-09610-8

Rauschenbach, C. and Hertel, G. (2011), “Age differences in strain and emotional reactivity to stressors in professional careers", Stress and Health, Vol. 27, e48-e60.

Roan, A. and Diamond, C. (2018). Starting Out: The Quality of Working Life of Young Workers in the Retail and Hospitality Industries in Australia. International Journal of Employment Studies, Vol. 11, No. 2, pp. 91-119. ISSN:1039-6993

Roe, D., Hasson-Ohayon, I., Derhi, O., Yanos, P. T., \& Lysaker, P. H. (2010) 'Talking about life and finding solutions to different hardships: a qualitative study on the impact of narrative enhancement and cognitive therapy on persons with serious mental illness.' The Journal of nervous and mental disease, 198(11), 807-812.

https://doi.org/10.1097/NMD.0b013e3181f97c50

Siu, O.I., Spector, P.E., Cooper, C.L. and Donald, I. (2001), “Age differences in coping and locus of control: a study of managerial stress in Hong Kong", Psychology and Aging, Vol. 16, No. 4, pp. 707-710. 
Sixth European Working Conditions Survey (2015). Available from:

https://www.eurofound.europa.eu/surveys/european-working-conditions-surveys/sixtheuropean-working-conditions-survey-2015

Snir, R. and Harpaz, I. (2021), 'Beyond workaholism: differences between heavy work investment (HWI) subtypes in well-being and health-related outcomes'. International Journal of Workplace Health Management, Vol. 14 No. 3, pp. 332-349. https://doi.org/10.1108/IJWHM-09-2020-0166

Susi, T., Shalvi, S. and Srinivas, M. (2019). 'I'll work on it over the weekend': high workload and other pressures faced by early-career researchers. Nature. doi: https://doi.org/10.1038/d41586-019-01914-z

Tarro, L., Llauradó E, Ulldemolins, G., Hermoso, P., and Solà R. (2020). Effectiveness of workplace interventions for improving absenteeism, productivity, and work ability of employees: a systematic review and meta-analysis of randomized controlled trials. International Journal of Environmental Research and Public Health, Vol. 17, No. 6. https://doi.org/10.3390/ijerph17061901

Taylor, D.C.M. and Hamdy, H. (2013). Adult learning theories: Implications for learning and teaching in medical education: AMEE Guide No. 83, Medical Teacher, Vol. 35, No. 11, e1561-e1572, DOI: 10.3109/0142159X.2013.828153

Theorell, T., Hammarström, A., Aronsson, G., Bendz, L.T., Grape, T., Hogstedt, C., and Hall C. (2015). A systematic review including meta-analysis of work environment and depressive symptoms. BMC Public Health, Vol. 15, No. 1, p. 738.

Torales J, O'Higgins M, Castaldelli-Maia JM, Ventriglio A. (2020). The outbreak of COVID-19 coronavirus and its impact on global mental health. International Journal of Social Psychiatry, Vol. 66, No. 4, pp. 317-320. doi: 10.1177/0020764020915212.

Victor, C.R. and Yang, K. (2012) The Prevalence of Loneliness Among Adults: A Case Study of the United Kingdom. The Journal of Psychology, Vol. 146, No. 1-2, pp. 85-104. doi: $10.1080 / 00223980.2011 .613875$

Wan Mohd Yunus, W.M.A., Musiat, P., Brown, J.S.L. (2018) 'Systematic review of universal and targeted workplace interventions for depression.' Occupational and Environmental Medicine, 75, 66-75. 
Workplace Wellbeing for Young Adults

Yoo, G. and Lee, S. (2018) 'It doesn't end there: workplace bullying, work-to-family conflict, and employee well-being in Korea.' International Journal of Environmental Research and Public Health, Vol. 15, No. 7, p. 1548.

YouGov. (2015). Available from URL: https://www.teachers.org.uk/node/24849 